\title{
The Development of a Canine Para-Agility Program: Positive Affects in Children with Autism and in Therapy Dogs
}

\author{
Denisa POP ${ }^{1,2}$, Alina S. RUSU ${ }^{1 *}$ and Vioara MIREȘAN ${ }^{2}$ \\ ${ }^{1)}$ Faculty of Psychology and Educational Sciences, Babes-Bolyai University, 1 Mihail Kogalniceanu \\ Street, Cluj-Napoca, Romania. \\ ${ }^{2)}$ Faculty of Animal Science and Biotechnologies, University of Agricultural Sciences and Veterinary \\ Medicine of Cluj-Napoca, 3-5 Manastur Street, 400372, Cluj-Napoca, Romania \\ *Corresponding authors, e-mail: alina.rusu@ubbcluj.ro
}

Bulletin UASVM Animal Science and Biotechnologies 73(1)/ 2016

Print ISSN 1843-5262; Electronic ISSN 1843-536X

DOI:10.15835/buasvmcn-asb: 11812

\begin{abstract}
Previous research has demonstrated that both children and dogs might benefit from Animal-Assisted Activities (AAA), with some factors mediating/ moderating the results. The present study took these factors into consideration, by creating an AAA program consisting of two types of human-animal interactions (structured and unstructured activities), with emphasis on the encouragement of positive behaviours. Differences in the frequency of behavioural indicators of positive affects were compared between sessions, in both species (humans and dogs). The preliminary analysis of the results indicated no significant differences between the structured and unstructured sessions in regards to the behavioural indicators of positive affects in humans and dogs, concluding that children and dogs enjoyed the activities in both types of sessions. A more in-depth statistical analysis is currently being performed.
\end{abstract}

Keywords: animal-assisted interventions, children with autism, therapy dogs, para-agility, positive affects

\section{INTRODUCTION}

Positive interactions between humans and dogs - such as play, petting, talking to the dog (Odendaal \& Meintjes, 2003) or even gazing into each other's eyes (Nagasawa et al., 2015) are known to bring benefits to both species, in terms of increasing their quality of life. From a physiological point of view, these benefits are due to the release of hormones such as oxytocin (Beetz et al., 2012), reduction of cortisol and changes in heart rate, heart rate variability and blood pressure (Odendaal, 2000; Pop et al., 2014).

Although autism is a developmental disorder characterized by impairments in social behaviour, communication and by restricted or stereotyped interests and behaviours (American Psychiatric Association, 1994), people with autism may also benefit from interacting with animals (O'Haire, 2013). Animal-Assisted Interventions
(AAI) provide opportunities for motivational, educational, recreational and/or therapeutic benefits to enhance the quality of human life (Pet Partners, n.d.). In the case of children with autism, animals can act as social buffers, conferring unique anxiolytic effects (O'Haire et al., 2015). It has been suggested that "there is low baseline cardiac parasympathetic activity with evidence of elevated sympathetic tone in children with autism" (Ming et al., 2005), which predisposes them to high levels of stress and anxiety. Hence, a possible explanation of the positive effects of AAI in the case of autistic children is that the parasympathetic nervous system (PNS) becomes activated through the positive behaviours mentioned above. Other positive outcomes of AAI in children with autism include an increase in social behaviours and a decrease in the number, duration and intensity 
of stereotypical behaviours (Redefer \& Goodman, 1989).

Regarding the dogs involved in the animalassisted interventions, several studies emphasised that forming a bond with a sentient being generates responsibilities to care for its needs (Burgess-Jackson, 1998) and, in the last ten years, more studies started to measure the well-being of the dogs as well, not only the improvements in the quality of human life. However, Haubenhofer and Kirchengast $(2006,2007)$ concluded that in those therapy dogs that work long hours without stops, the cortisol levels were increased, as well as in the case of the therapy dogs that were kept in lead for a long time (Glenk et al., 2013), indicating a high level of stress. The level of stress was alleviated by getting familiar with the people in the therapy and to the therapeutic environment (Glenk et al., 2014).

Hence, the purpose for the development of this program was to ensure that both children and dogs enjoy the interactions, thus taking maximum advantage of the potential positive effects of HAI. The structured sessions were compared to the unstructured sessions, in terms of the frequency of positive affects that appeared during the interaction in each situation. We present here only the analysis of the total numbers of the behavioural indicators of positive affects recorded for each session. An in depth analysis of each type of behavioural indicator in currently being analysed.

\section{MATERIALS AND METHODS}

Participants

Thirteen children between the ages of 3 and 12 years, attending an Autism Centre (Transylvania Autism Centre, Cluj-Napoca, Romania) were recruited in the programme, but only eleven of them participated in the activities (nine boys, two girls). Five of the children were diagnosed with autism and the other eight had symptoms such as attention deficits, language acquisition delays, motor coordination problems, but not a specific diagnosis. Each child was able to communicate using verbalization and each of them was able to walk. Written informed consent was obtained from the parents. The program took place outdoors, from April to July (2015).

Six dogs of different breeds interacted individually with the children. They were certified therapy dogs or in training, belonging to the Pet

Table 1. Behavioural indicators (activity, gestures, postures) of positive affects in children towards the dog, recorded in frequency of occurrence.

\begin{tabular}{ccc}
\hline Category & Code & Description \\
\hline Activity & Pet the dog & The child pets the dog \\
\hline & Touch the dog & The child touches the dog \\
\hline & Play with the dog & The child plays with the dog, usually by throwing him a ball \\
\hline & Gazing into the dog's eyes & The child looks into the dog's eyes \\
\hline Behaviour & Smile & The child smiles after interacting with the dog \\
\hline & Laugh & The child laughs after interacting with the dog \\
\hline
\end{tabular}

Table 2. Behavioural indicators of positive affects in dogs towards children, recorded in frequency of occurrence.

\begin{tabular}{|c|c|c|}
\hline Category & Code & Description \\
\hline \multirow[t]{2}{*}{ Activity } & Playing with the human & $\begin{array}{c}\text { The dog plays with the child, usually by throwing him } \\
\text { a ball }\end{array}$ \\
\hline & $\begin{array}{l}\text { Gazing into the human's } \\
\text { eyes }\end{array}$ & $\begin{array}{c}\text { The dog looks into the child's } \\
\text { eyes }\end{array}$ \\
\hline \multicolumn{3}{|c|}{ Response to human } \\
\hline \multicolumn{3}{|c|}{ Being petted by the human The dog gets petted by the child } \\
\hline & $\begin{array}{l}\text { Being touched by the } \\
\text { human }\end{array}$ & $\begin{array}{l}\text { The dog gets touched by the } \\
\text { child }\end{array}$ \\
\hline
\end{tabular}


Joy Dog Training School (Cluj-Napoca, Romania). The handlers were also trained individuals.

The children were accompanied by certified psychotherapists, who were prompting them when needed.

Setting and procedure

Four structured (SS) and four unstructured sessions (US) took place at the Autism Centre, where the children came for therapy every day. Each session had a duration of $20 \mathrm{~min}$. In the structured sessions, the dogs were led individually by the children through an agility arena, consisting of a line of five obstacles and a play tunnel $(3 \mathrm{~m}$ long). In the unstructured interaction sessions, the dogs and children were allowed to play freely, being supervised by a trained handler. The structured sessions were designed in a way that encouraged positive interactions, but also gave the children and dogs the opportunity to do a little physical activity. Yanardağ et al. (2010) suggested that exercise and sport activities are not supplied enough for children with autism even if they were shown to decrease motor failures and provide social integration.

After participating in a structured session, the children went on and participated in an unstructured session. Some of the children did not undergo this succession due to some external

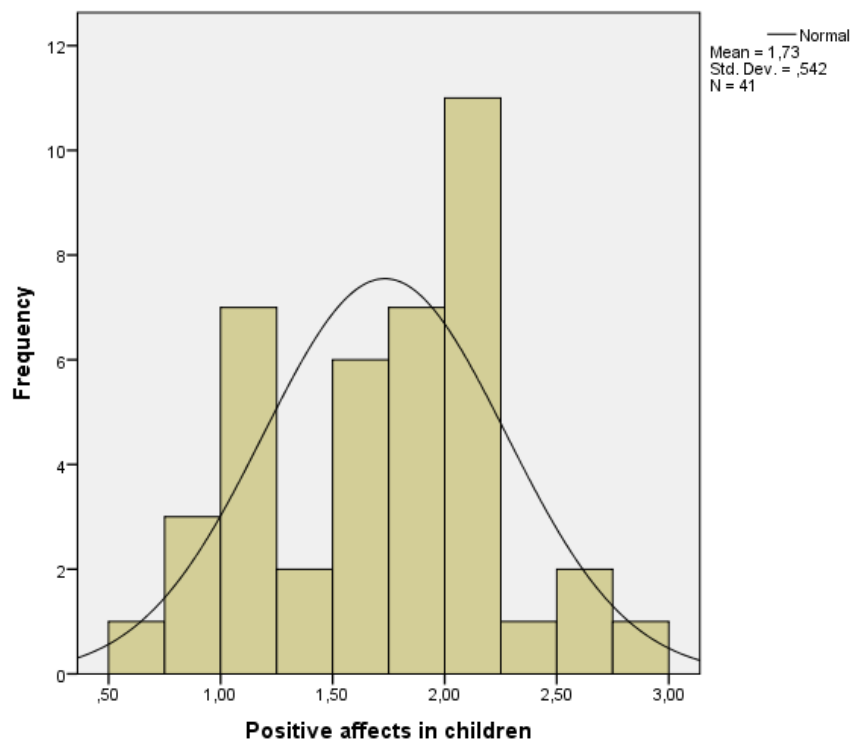

Fig.1. Transformed scores for the behavioural indicators of the positive affects towards dogs in children factors (i.e. weather, sudden changes in the agenda).

The sessions were recorded with a GoPro Camera and a Sony Handycam. The recorded materials were analysed frame by frame using Continuous Sampling Method and Focal Individual Analysis. The total number of interpretable sessions was 28 structured sessions (SS) and 13 unstructured sessions (US) for the children, and 27 structured sessions (SS) and 7 unstructured sessions (US) for the dogs. For each session, chains of sequences were generated, then transition matrices and the relative frequencies (i.e., occurrence of behavioural unit per 60 seconds) were calculated.

The positive affect behaviours in children (Table 1) and dogs (Table 2) were chosen in accordance with previous studies which found several correlations between these behaviours and physiological changes, such as indicators of parasympathetic nervous system activation and well-being: gazing into each other's eyes (Nagasawa et al., 2015), petting and playing with the dog (Odendaal, 2000; Odendaal \& Meintjes, 2003; Handlin et al., 2011; Handlin et al., 2012), laughter andsmile(Soussignan, 2002). Thenumber of occurrences for the behavioural indicators of positive affects was summed up for each session and their relative frequencies were calculated in

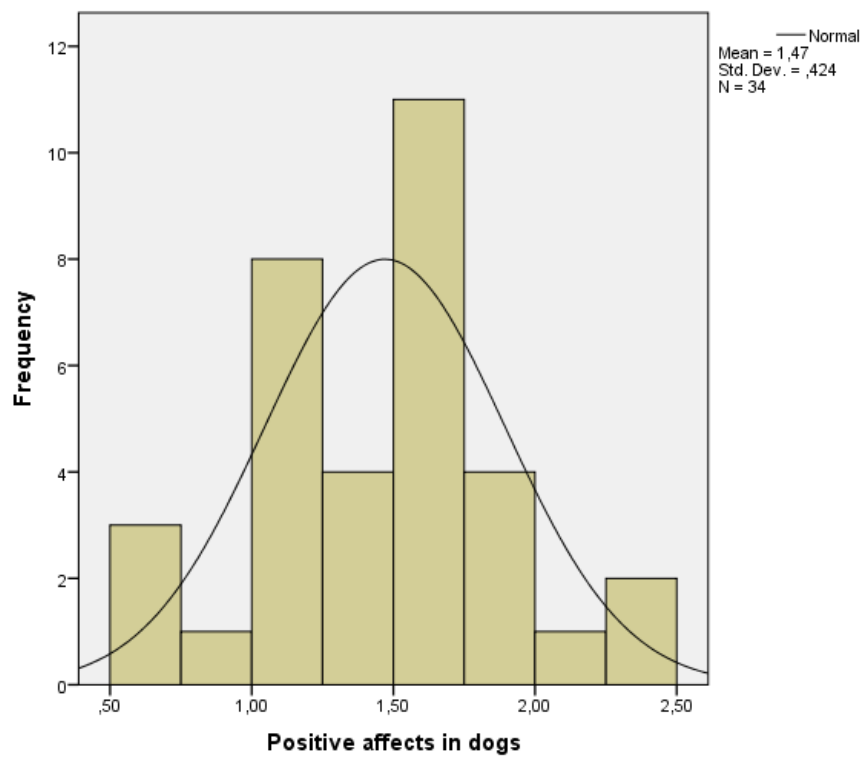

Fig.2. Transformed scores for the behavioural indicators of the positive affects towards children in dogs. 
order to compare the SS were compared to the US in terms of positive affects.

\section{RESULTS AND DISCUSSION}

The data initially followed a Poisson distribution, but it was transformed into a Gaussian one using square root transformation in SPSS (Fig. 1 and Fig. 2).

Taking into consideration the difference between groups (Table 3 ) in children $(\mathrm{N}=13$ US and $\mathrm{N}=28 \mathrm{SS}$ ) and the one between groups (Table 4) in $\operatorname{dog}(\mathrm{N}=7$ US and $\mathrm{N}=27 \mathrm{SS}$ ), the Levene test was used to measure the homogeneity of variances in each situation. The homogeneity was maintained between groups in children $(p=0.28)$ and in dogs as well $(p=0.60)$.

Using One-Way ANOVA, the relative frequencies of behavioural indicators of positive affects (i.e., children towards dogs and dogs

Table 3. Frequency of the behavioural indicators of positive affects in children towards dogs in the unstructured (US) and structured (SS) sessions.

\begin{tabular}{|c|c|c|c|}
\hline & $\mathrm{N}$ & Mean & Std. Deviation \\
\hline US & 13 & 1.636 & .715 \\
\hline SS & 28 & 1.777 & .448 \\
\hline Total & 41 & 1.732 & .541 \\
\hline
\end{tabular}

towards children) were compared between the unstructured and structured sessions. The OneWay ANOVA in children ( $F=0.603, p=0.442$ ) showed no significant differences between SS and US regarding the positive affects towards dogs (Fig. 3), meaning that a similar frequency of affects appeared in both sessions.

Similarly, the One-Way ANOVA in dogs $(\mathrm{F}=1.862, \mathrm{p}=0.182)$ showed no significant differences between SS and US regarding the frequency of the positive affects towards children (Fig. 4), meaning that a similar frequency of affects appeared in both sessions.

Hirstein et al. (2001) recommend that children with autism engage in relaxing activities to avoid a chronically high sympathetic activity. AnimalAssisted Interventions might be included in this category. Compared to other kinds of activities or even therapy, AAI have a greater impact on

Table 4. Frequency of the behavioural indicators of positive affects in dogs towards children in the unstructured (US) and structured (SS) sessions.

\begin{tabular}{|c|c|c|c|}
\hline & $\mathrm{N}$ & Mean & Std. Deviation \\
\hline US & 7 & 1.662 & .421 \\
\hline SS & 27 & 1.420 & .417 \\
\hline Total & 34 & 1.470 & .423 \\
\hline
\end{tabular}

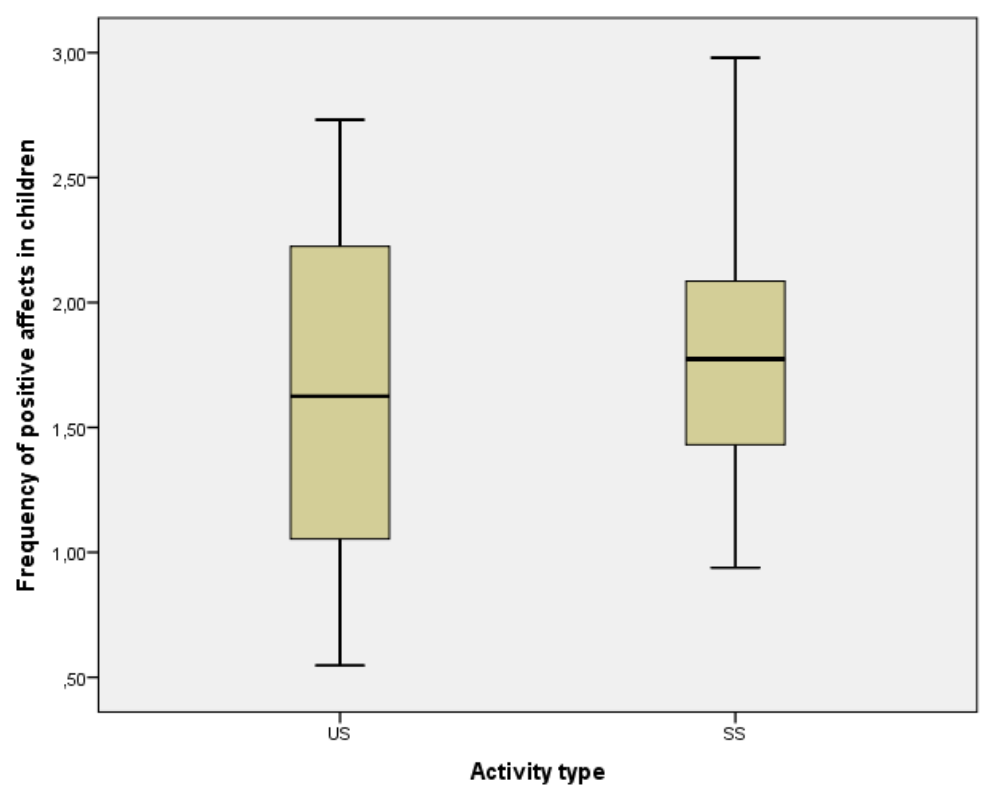

Fig 3. The frequency of positive affects towards dog in children in unstructured (US) versus structured (SS) sessions. 


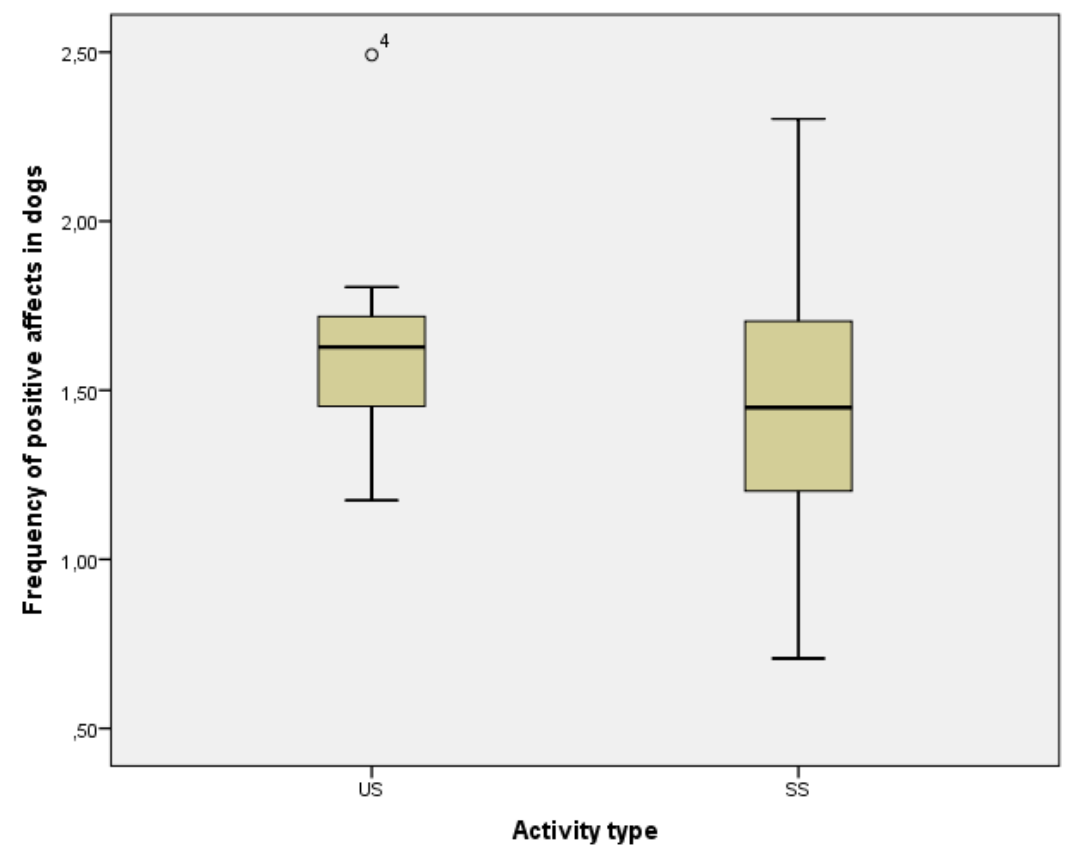

Fig 4. The frequency of positive affects towards children in dogs in unstructured (US) versus structured (SS) sessions.

the child, such as the increase of overall positive initiated behaviours (Walters Esteves and Stokes, 2008 ) or the use of language and social interaction (Sams et al., 2006).

The present study aimed to compare structured sessions of animal-assisted activities (in which the child guides the dog through an established agility route and positive interaction was encouraged by the therapist and by the dog handler) with unstructured sessions (in which the child and the dog were allowed to interact freely). Although the differences between SS and US regarding the total number of the behavioural indicators of positive affects was not significant in either dogs or children, in each type of session, there were different predominant affects. For example, in the children's SS, the predominant behaviour was petting the dog, while in the US the predominant one was playing with the dog (Note: data for each type of behavioural indicator are currently being analysed). For the dogs, it was noticed that in the SS, they were mostly petted, while in the US, they mostly played with the children.

\section{CONCLUSION}

This preliminary statistical analysis indicates that both types of sessions (structured and unstructured activities) contain behavioural indicators of positive affects towards the other being participating in the activities, such as smile, laughing and prosocial behaviours (children towards dogs) and acceptance of petting and gazing in the case of dogs towards children.

The next step of our investigation is to analyse each type of behavioural indicator and create a hierarchy of positive affects for each type of session. Such a hierarchy might help the therapists and the parents to design healthy animal-assisted activities (in terms of respecting the well-being of the therapy animals), based on the specific socioemotional needs of each child.

Acknowledgement: This study is part of the research grant PN-II-PT-PCCA-2013-4-0781 (director: Alina S. Rusu, Babes-Bolyai University). The authors would like to thank Anamaria Basceanu for participating to the unstructured activities with her dog, as well as to the behavioural data coding. Special thanks go to the members of the Pet Joy Training School for participating to this program with their therapy dogs and to MariusIoan Groza for helping with data analysis.

\section{RFERENCES}

1. American Psychiatric Association. (1994). Diagnostic and statistical manual of mental disorders (4th ed.). Washington, DC. 
2. Burgess-Jackson K. (1998). Doing right by our companion animals. The Journal of Ethics, 2, 159-185.

3. Esteves SW, Stokes T. (2008). Social effects of a dog's presence on children with disabilities. Anthrozoös, 21, 515.

4. Glenk L, Kothgassner O, Stetina B, Palme R, Kepplinger B, Baran H. (2013). Therapy dogs' salivary cortisol levels vary during animal-assisted interventions. Animal Welfare, 22, 369-378.

5. Glenk L, Kothgassner O, Stetina B, Palme R, Kepplinger B, Baran H. (2014). Salivary cortisol and behavior in therapy dogs during animal-assisted interventions: A pilot study. Journal of Veterinary Behavior, 9, 98-106.

6. Handlin L, Hydbring-Sandberg E, Nilsson A, Ejdebäck M, Jansson A, Uvnäs-Moberg K. (2011). Short-Term Interaction between Dogs and Their Owners: Effects on Oxytocin, Cortisol, Insulin and Heart Rate - An Exploratory Study. Anthrozoos: A Multidisciplinary Journal of The Interactions of People \& Animals, 24, 301-315.

7. Handlin L, Nilsson A, Ejdebäck M, Hydbring-Sandberg E, Uvnäs-Moberg K. (2012). Associations between the Psychological Characteristics of the Human-Dog Relationship and Oxytocin and Cortisol Levels. Anthrozoos: A Multidisciplinary Journal of The Interactions of People \& Animals, 25, 215-228.

8. Haubenhofer D, Kirchengast S. (2006). Physiological Arousal for Companion Dogs Working With Their Owners in Animal-Assisted Activities and Animal-Assisted Therapy. Journal of Applied Animal Welfare Science, 9, 165172.

9. Haubenhofer D, Kirchengast S. (2007). “Dog Handlers" and Dogs' Emotional and Cortisol Secretion Responses Associated with Animal-Aassisted Therapy Sessions. Society \& Animals, 15, 127-150.

10. Ming X, Julu PO, Brimacombe M, Connor S, Daniels ML. (2005). Reduced cardiac parasympathetic activity in children with autism.Brain and Development, 27, 509-516.

11. Nagasawa M, Mitsui S, En S, Ohtani N, Ohta M, Sakuma Y, Onaka T, Mogi K, Kikusui T (2015). Oxytocin-gaze positive loop and the coevolution of human-dog bonds. Science, 348,333-336.
12. Odendaal JSJ. (2000). Animal-assisted therapy - magic or medicine? Journal of Psychosomatic Research, 48, 27580.

13. Odendaal JSJ, Meintjes RA. (2003). Neurophysiological correlates of affliative behavior between humans and dogs. The Veterinary Journal, 165, 296-301.

14. O'Haire ME, McKenzie SJ, Beck AM, Slaughter V. (2013). Social Behaviors Increase in Children with Autism in the Presence of Animals Compared to Toys. PLOS ONE, 8, 1-10.

15. O'Haire ME, McKenzie SJ, Beck AM, Slaughter V. (2015). Animals may act as social buffers: Skin conductance arousal in children with autism spectrum disorder in a social context. Dev. Psychobiol., 57, 584-595.

16. Pet Partners (n.d.). About animal-assisted activities \& animal-assisted therapy. Available at http://www. petpartners.org/.

17. Pop D, Rusu AS, Pop-Vancia V, Papuc I, Constantinescu R, Mireșan, V. (2014). Physiological Effects of Human-Animal Positive Interaction in Dogs - Review of the Literature, Bulletin of UASVM, 71, 102-110.

18. Redefer LA, Goodman JF. (1989). Brief report: Petfacilitated therapy with autistic children. Journal of Autism and Developmental Disorders, 19, 461-467.

19. Sams MJ, Fortney EV, Willenbring S. (2006). Occupational therapy incorporating animals for children with autism: A pilot investigation.American Journal of Occupational Therapy, 60, 268-274.

20. Soussignan R. (2002). Duchenne Smile, Emotional Experience, and Autonomic Reactivity: A Test of the Facial Feedback Hypothesis, Emotion, 2, 52-74.

21. Hirstein W, Iversen P, Ramachandran VS. (2001). Autonomic responses of autistic children to people and objects. Proceedings of the Royal Society of London B: Biological Sciences,268,1883-1888. Yanardağ M, İlker Y, Aras Ö. (2010). Approaches to the Teaching Exercise and Sports for the Children with Autism, International Journal of Early Childhood, 2, 214-230. 